4

\title{
Animal Learning as a Source of Developmental Bias
}

6

7

8

9

10

11

12

13

14

15

16

17

18

19
Kevin N Laland ${ }^{1}$, Wataru Toyokawa ${ }^{1,2,3}$ \& Thomas Oudman ${ }^{1,4}$

${ }^{1}$ School of Biology, University of St Andrews, St Andrews, UK

2 Department of Evolutionary Studies of Biosystems, SOKENDAI (The Graduate University for Advanced Studies), Hayama, Kanagawa 240-0193, Japan

${ }^{3}$ Current address: Department of Psychology, University of Konstanz, Germany

${ }^{4}$ NIOZ Royal Netherlands Institute for Sea Research, Department of Coastal Systems, and Utrecht University, The Netherlands

The authors declare that they have no relevant conflicts of interest.

Article: Laland, KN, Toyokawa, W \& Oudman, T 2019, 'Animal learning as a source of developmental bias' Evolution and Development, vol. Early View, e12311. https://doi.org/10.1111/ede.12311

Pure ID: 260877183

Author accepted manuscript (accepted August 10 2019) 
31 ABStRACt. As a form of adaptive plasticity that allows organisms to shift their phenotype toward the optimum, learning is inherently a source of developmental bias. Learning may be of particular significance to the evolutionary biology community because it allows animals to generate adaptively biased novel behavior tuned to the environment and, through social learning, to propagate behavioral traits to other individuals, also in an adaptively biased manner. We describe several types of developmental bias manifest in learning, including an adaptive bias, historical bias, origination bias and transmission bias, stressing that these can influence evolutionary dynamics through generating nonrandom phenotypic variation and/or nonrandom environmental states. Theoretical models and empirical data have established that learning can impose direction on adaptive evolution, affect evolutionary rates (both speeding up and slowing down responses to selection under different conditions), and outcomes, influence the probability of populations reaching global optimum, and affect evolvability. Learning is characterized by highly specific, path-dependent interactions with the (social and physical) environment, often resulting in new phenotypic outcomes. Consequently, learning regularly introduces novelty into phenotype space. These considerations imply that learning may commonly generate plasticity first evolution.

KEYWORDS: Learning, developmental bias, plasticity, plasticity first, evolvability

RESEARCH HIGHLIGHTS: Learning is a major source of developmental bias in animals. Here we review the different types of developmental bias manifest in learning, and show how these influence evolutionary dynamics. 
54 A central, largely unresolved, issue in the field of evolutionary biology is whether and how developmental processes contribute to evolutionary change (Love 2015), and one muchdiscussed means by which development might do so is through generating a biased distribution of phenotypic variation (i.e. 'developmental bias'; Maynard-Smith et al 1995; Brakefield, 2006; Uller et al 2018). Perhaps some developmental biologists will not think of learning as a 'developmental' process, as it is typically studied without consideration of gastrulation, cell division or hox genes. However, if development is viewed broadly to comprise all of the changes in size, shape, and function that take place during the life of an organism, learning is unquestionably a developmental process. Viewed in this manner, any biases in behavioral phenotypes that are generated through learning are a form of developmental bias.

This point takes on new significance once some well-documented properties of learning are recognized. What is immediately apparent to most students of animal learning, but perhaps less obvious to many other biologists, is that learning typically is a highly flexible form of adaptive plasticity that shifts many aspects of the phenotype towards the optimum. Also selfapparent is the fact that animals commonly learn knowledge and skills through observing and interacting with other animals, including other species, again with a strong tendency to acquire adaptive knowledge.

In this article we describe how phenotypes generated through animal learning are generally not just biased, but adaptively biased. Moreover, such phenotypes are not just manifest in a single individual but commonly rapidly propagated to multiple individuals and, through social transmission, passed on to descendants. We also review the evidence that novel phenotypes propagated through learning can impact genetic evolution. Here we set out to present the evidence, both experimental and theoretical, that leads us to the view that learning should be regarded as an important source of developmental bias in animals, and a profound influence on adaptive evolution.

\section{DEFINITIONS}

What is developmental bias?

The term 'developmental bias', as commonly deployed, is somewhat ambiguous because it is 
manifestly subject to two distinct readings: Is it the products of development that are biased (i.e. are a biased set of phenotypic variants generated)? Or are developmental processes biasing something else - most obviously, the course of evolution? While the most evident way in which developmental processes can bias the course of evolution is through biasing phenotypic variation, in principle, these two readings can be disassociated. Biased phenotypic variation need not affect the course of evolution (e.g. if dynamics are dominated by selection), whilst developmental processes could affect the course of evolution even if phenotypic variation were isotropic (e.g. through nonrandom modification of selective environments). We suspect that usage of the term slips between these two meanings, with users perhaps sometimes unaware of the inherent ambiguity, and frequently committed to both interpretations. This slippage may partly account for the diversity of usage of this term. One way of resolving the ambiguity is to distinguish between the two usages explicitly: that is, distinguishing between a biased product of development (henceforth 'developmentally biased phenotypic variation'), and a biasing process of development ('developmentally biased evolutionary process'). This approach has proven useful in helping to clarify a similar ambiguity in the use of the term 'innovation' (Reader \& Laland, 2003).

To characterize the process or the product of development as 'biased' we must have some notion of what an unbiased product/process would look like. Hence, ideally a definition of developmental bias would state relative to what baseline the bias arises. Here, following Uller et al (2018, p949), we define developmentally biased phenotypic variation as 'the bias imposed on the distribution of phenotypic variation, arising from the structure, character, composition, or dynamics of the developmental system, relative to the assumption of isotropic variation'. We also define a developmentally biased evolutionary process as 'any bias in the rate, dynamics and pattern of evolution arising from the production of nonrandom phenotypic variation (broadly construed), relative to the expected rate, dynamics and pattern of evolution arising from random genetic variation.'

We introduce the qualification 'broadly construed' as our use of this term will encompass cases in which organisms express their nonrandom (extended) phenotypic variation in the external environment, for instance through building nests, burrows, mounds, webs, and pupal cases, or modifying local soils, hydrology, chemistry, nutrients, or flows (i.e. niche construction), and which thereby bias the sources of selection that they, and other ecologically interacting populations, experience (Odling-Smee et al, 2003; Laland et al., in 
press).

119 In this article, we are interested in both the specific form of developmentally biased 120 phenotypic variation that arises from animal learning, and in its evolutionary consequences. 121 We suggest that the forms of bias that result from learning are of relevance to the 122 evolutionary biology community because, (1) through learning, animals tune their behavior 123 to environments, including novel environments, by selectively generating, retaining and refining adaptive behaviors more readily than non-adaptive ones. Moreover, (2) these adaptive novel phenotypic variants are commonly propagated to other individuals, including nonrelatives, and across generations, through social learning. This social transmission of behavior is a second source of bias towards the propagation of adaptive variants - evidence from diverse species of animals demonstrates that the likelihood of social transmission of novel learned knowledge and skills is significantly higher for adaptive than for non-adaptive behavioral variants. In addition, (3) learned and socially transmitted behavior can bring about consistent changes in the social and ecological environments, thereby biasing the selective environment of both the learner and of other species that experience modified conditions (i.e. niche construction). We submit that by generating and propagating novel phenotypes that are adaptive (i.e. nonrandom with respect to fitness), and modifying selective environments in reliable ways, animal learning biases the course of evolution. We go on to make further distinctions between different types of developmental bias manifest in, and resulting from, learning (Table 1).

What is animal learning?

140 Learning is generally defined as a relatively permanent change in behavior (or potential 141 behavior) that results from experience (Dickinson 1981; Rescorla, 1988; Kirkpatrick \& Hall, 2004). Central to definitions of learning is the requirement that there must be a memory trace of what has been learned, allowing the animal on subsequent occasions to recall or do what they have learned previously. Transient changes, such as reflexes, do not qualify. Learning is usually inferred from changes in observable behavior, but is not always immediately manifest, and can be stored to influence future performance.

There are many forms of learning (Kirkpatrick \& Hall, 2004; Staddon 2016). Animals may learn about a single event through habituation or sensitization, or form associations

149 between events, which includes 'classical' (a.k.a. 'Pavlovian') and 'operant' (a.k.a. 
'instrumental') conditioning. The latter is of most interest here, as it is thought to be the

151 primary means by which animals acquire behaviour (Staddon, 2016). This kind of learning

152 occurs through reinforcement, in which positive or negative experiences provide animals with

153 a mechanism for the selection of appropriate behavior. Actions that bring about positive

154 consequences (e.g. finding food, avoiding danger) are more likely to be performed in the

155 future, whilst those with negative consequences (causing pain, missing out on reward)

156 become less likely. Such actions occur in a particular context, or in response to a particular

157 cue, and the learning that takes place is described as 'associative' because the animal learns

158 to produce the action in response to the cue (i.e. stimulus-response learning) or else learns that the action has a particular consequence (i.e. response-reinforcement learning).

That animals learn through operant conditioning has been known for a long time

161 (Thorndike, 1898) and has been demonstrated in so many species, including countless invertebrates, that it is commonly regarded as virtually universal across animals. Skinner (1938) stressed three general features of animal learning: (i) animals are frequently active, and hence are continuously emitting behavior; (ii) these emitted behavior patterns frequently have consequences that influence the frequency with which the behavior is repeated in the future; and (iii) the effects of the consequences are influenced by the animal's motivational state, as well as by the physical and social environment. The first of these is rarely emphasized, but important. Learned behavior is often the result of an exploratory search conducted over multiple trials, through which individuals hone their behavior to exploit their environment. This exploratory component to learning is significant, because it generates behavioral flexibility and variability. There is seemingly no end to the associations that many animals could form.

In their natural environment, animals frequently learn from other individuals. In this manner, animals rapidly acquire skills and functional information concerning what to eat, where to find it, how to process it, pathways to take through their environment, what a predator looks like, how to escape the predator, calls, songs, and more (Hoppitt \& Laland, 2013). Social learning is defined as learning that is facilitated by observation of, or interaction with, another individual or its products (Heyes 1994; Hoppitt \& Laland 2013). It is also widespread amongst animals, including invertebrates, and even in species described as 'solitary' (Wilkinson et al, 2010). Theoretical analyses and experimental studies both strongly suggest that social learning is more efficient than individuals learning alone, for instance, 
through trial-and-error (Rendell et al, 2010; Hoppitt \& Laland, 2013). That is because when animals learn socially, the aforementioned 'exploratory search' is effectively expanded to encompass the trials and associated experiences of multiple individuals. Social learning is particularly valuable in helping animals to solve difficult problems where the optimal action is one of many possible actions, or when a long sequence of actions is required to be performed in the correct order to elicit the reward (Whalen et al, 2015). If finding the optimal behavior is like searching for a needle in a haystack, then learning is as if someone tells you when you are getting close (Hinton \& Nowlan, 1987; Maynard Smith 1987); social learning is when someone actually shows you where to look.

Social learning occurs throughout the lifespan, and from many different individuals, and thereby allows for the propagation of phenotypic variants amongst unrelated individuals, often within timespans significantly shorter than a generation (e.g. social transmission of predator recognition in minnows, Pimphales promelas; Chivers \& Smith 1995; socially learned mating preferences in grouse, Centrocercus urophasianus; Gibson et al, 1991). Socially transmitted activities (e.g. foraging) can modify ecological circumstances, sometimes in ways that feed back to impact natural selection (niche construction). Social learning generates an additional mechanism of inheritance operating parallel to genes 'cultural inheritance') (Hoppitt \& Laland 2013; Whiten et al. 2017).

\section{Biases in Phenotypic Variation aRIsing from ANimal Learning}

202 This section focuses on developmentally biased phenotypic variation resulting from animal learning.

Biases arising from individual learning

Experimental research in a very large number of species of animals provides compelling evidence that learning typically increases the rate of reinforcement, and reduces the rate of punishment, experienced by animals (Dickinson 1980; Kamil, 1983; Kirkpatrick \& Hall, 2004; Staddon, 2007, 2016). Faced with multiple potential food sites, an animal will typically sample the alternatives and choose the option yielding the highest return. The decision made, the amount of sampling, the number of times the animal performs the action (e.g. if on a 'fixedreinforcement schedule'), the timing of the performance (e.g. when on an interval schedule'), and other parameters, have all been reliably shown to improve over trials with 
214 relevant experience (Krebs et al, 1978; Dickinson 1980; Kamil, 1983; Kirkpatrick \& Hall, 2004;

215 Staddon, 2016). Similar findings apply to learning to avoid threats.

216 This kind of associative learning is widespread and has general properties that allow

217 animals to learn about the causal relationships among a wide variety of events (Dickinson,

218 1980; Mackintosh, 1974). Learning can occur through quite simple rules. One example is the

219 theory known as the Rescorla-Wagner rule, which describes updates in knowledge as a linear

220 combination of current knowledge and new information. It has proved useful in explaining

221 the results of experiments on foraging in honeybees, avoidance conditioning in goldfish, and

222 inferential reasoning in humans (Rescorla \& Wagner, 1972).

223

Thirty years ago, inspired by optimal foraging theory (Stephens \& Krebs, 1986), there

224 was extensive theoretical interest in the idea that learned behavior might maximize the rate

225 of reinforcement, and thereby generate optimal behavior (Kamil, 1983; Staddon, 2007). That

226 particular research agenda met only partial success (Staddon, 2007): animals were found to

227 learn optimally only under restricted conditions, with their behavior often following

228 mechanical rules that seemingly evolved to produce close-to-optimal behavior only under

229 natural conditions encountered by the species during its evolutionary history. Yet this does

230 not undermine the general conclusion that the learned behavior of animals is typically

231 adaptive, and that reinforcement learning generally shifts behavior towards the optimum.

232 Learning is adaptive precisely because animals have been fashioned by evolution actively to

233 seek out high-fitness behavioral outcomes, and to forestall activities that might negatively

234 impact their survival and reproduction (Pulliam \& Dunford 1980; Staddon 2016).

235 Skinner's (1953) bold claim that "reinforcement shapes behavior as a sculptor shapes

236 a lump of clay" somewhat exaggerates the power of reward and punishment to influence

237 behavior. In practice, evolved predispositions bias what learning takes place (a.k.a.

238 'constraints on learning'; Hinde \& Stephenson-Hinde, 1973). Garcia and Koelling (1966)

239 famously gave rats food and then radiation that made them sick. The rats tended

240 subsequently to avoid food with that taste or smell, but struggled to learn an association

241 between other characteristics of the food and sickness, and were extremely slow to learn that

242 a sound or light predicts illness. From an evolutionary perspective, this makes sense, as

243 sickness generally results from eating rather than from noises or lights and taste is a reliable

244 indicator of a food's nature. Likewise, Mineka and Cook (1988) demonstrated that laboratory-

245 reared, juvenile rhesus monkeys exhibit fear responses to snakes only after watching adults 
respond fearfully to snakes. The monkeys failed to acquire fear responses to either a toy rabbit or flowers after watching video sequences of conspecifics appearing to behave fearfully toward them, but such video presentations were sufficient to induce fear of snake-like stimuli. Interestingly, an earlier study had found that these monkeys could be socially conditioned to fear other arbitrary stimuli (kitchen utensils) (Stephenson 1967). A similar study of blackbirds, which learn to recognize predators through attending to the mobbing behavior of conspecifics, also found that they could be conditioned to acquire a fear of arbitrary objects, in this case, plastic bottles, in this manner (Vieth et al., 1980; Curio, 1988). Seemingly, the monkeys have evolved a perceptual bias that enhances the salience of snake-shaped stimuli, making it easier for them to learn about snakes than flowerpots, but not precluding their acquiring fears of novel stimuli through observational conditioning. In comparison, the blackbirds do not yet seem to have evolved this kind of perceptual bias. The adaptive value of an observational-conditioning mechanism, whereby animals learn to be fearful of objects or events that conspecifics fear, is easy to envisage. Sensitivity to persistent threats (e.g. snakes, in the case of monkeys) can be heightened through natural selection up-regulating the salience of such stimuli, yet the general observational-conditioning mechanism allows the animal to learn about novel threats with rapidity and flexibility.

These data suggest that learned behavior is neither always optimal, nor infinitely malleable through reinforcement. Animal learning typically begins with an exploratory search or sampling procedure, and the initial trials may not be biased towards adaptive decisions (e.g. in which direction to search of food, or which food patch to try first). However, after a small number of trials the animal's behavior will adjust to the patterns of reinforcement encountered. The final form of the behavior, after repeated trials, is generally highly adaptive (foraging efficiency is enhanced, the best food patch is selected, dangers are avoided, and so forth) (Staddon, 2016). This generic shift towards adaptive or optimal behavior as a consequence of reinforcement learning we label here an adaptive bias (see Table 1).

Learning may generally be adaptive but it is not universally optimal. Evolved predispositions themselves bias the learning process, a phenomenon that we refer to as an historical bias (see Table 1). Seemingly, animals have been tuned by their evolutionary history to form some associations more readily than others, or to perform particular actions in particular contexts. Apparently, ancestral natural selection has fashioned dedicated learning predispositions or motivational priorities tailored to the particular ecological circumstances 
of each species. However, the generality of the observed mechanisms of learning imply that the observed species-specificity is better regarded as selection tinkering with a general system than as selection constructing an independent set of species-specific learning processes (Bolhuis \& MacPhail, 2001). What an animal learns may vary adaptively between species, but how animals learn appears to be broadly similar across diverse taxa (Shettleworth, 2000).

Nonetheless, the aforementioned literature also makes it clear that historical biases exert a probabilistic influence on learning and are rarely hard or prohibitive constraints. This is because learning by definition results from historically contingent experiences, which often depend on complex interactions between many environmental factors. For example, why an animal learns to forage on one specific food type instead of another may be because of the idiosyncratic sequence of food items it encountered during earlier decision-making episodes. Such contingencies could not have been predicted at the outset of its development because of chance events experienced, the recursive interactions between learning on many environmental factors, and decision-making based upon the knowledge of other individuals in the local environment. This contrasts with many other sources of phenotypic plasticity that can more satisfactorily be characterized as reaction norms to an environmental factor (but see Sultan, forthcoming). On the one hand, this means that the existence of evolutionary biases on learning cannot always prevent the coincidental development of non-adaptive behavior, even under normal environmental conditions. On the other hand, it means that evolutionary biases do not preclude the acquisition of entirely novel and yet adaptively biased behavior, one consequence of which is that learning is a major source of behavioral innovation.

Through learning, for instance, how to discover and exploit new foods, or devising novel means to escape or avoid a threat, animals can introduce new behavior into the population's repertoire. Such instances are labeled behavioral innovations, defined by Reader \& Laland, (2003, p 14) as new or modified learned behavior not previously found in the population. Innovations are novel functional solutions tailored to new challenges or hitherto unexploited opportunities. Not all cases of learning result in innovation, since animals frequently learn associations that other members of their population have learned previously. However, behavioral innovation, as currently generally understood, requires learning, since otherwise innovation could not be distinguished from exploration, or from any idiosyncratic 
310 or accidental behavior (Reader \& Laland, 2003). Learned behavioral innovation is now 311 extensively documented in animals (Reader \& Laland, 2003; Reader et al, 2016). Examples 312 include killdeer feeding on live frogs (a novel food item; Scharsien \& Jackson, 1982), 313 Northwestern crows fishing for sand eels by digging in the sand at low tide (i.e. inventing 314 novel foraging technique; Robinette \& $\mathrm{Ha}, 1997)$, and New Caledonian crows crafting hooked 315 tools for foraging (e.g. devising novel tools; St Clair et al. 2018). Learned behavioral 316 innovations are thus novel phenotypes - traits not previously observed in the lineage. 317 However, while analogous to genetic mutation in the respect that they introduce novel 318 variation, as the above examples highlight, behavioral innovations are usually not random but exhibit an adaptive bias (Snell-Rood et al, 2018).

Innovations may also exhibit historical biases. Perhaps the most famous example of an animal innovation is the invention of the habit of washing sweet potatoes in water by Japanese macaques (Kawai, 1965). Subsequent research established that food washing is common in several species of macaques, which means that this particular innovation involved the application of an established behavior to a novel food (Reader \& Laland, 2003). In fact, many animal innovations fall into this category of established behavior applied in a novel context, or to a novel stimulus (Reader \& Laland, 2003; Reader et al, 2016). Behavioural innovation through learning commonly allows the generalization or new application of a behavioral phenotype to novel environments or contexts, as well as the de novo invention of novel solutions. There is a lot of interest currently in whether organisms adapt to the rapidly changing world, and the role that plasticity plays in this (Snell-Rood et al, 2018; Fox et al, 2019), but few articles in a recent special edition on this topic (Fox et al, 2019) even mention learning. Nonetheless, this community have stressed how the processes of plasticity and adaptation, traditionally considered independently of each other, need to be viewed synergistically (Fox et al, 2019). Greater attention to how animals adjust to novel environments through learning is surely merited.

Additionally, unlike genetic mutations, which generally occur equally likely across all members of the population, behavioral innovations may be significantly more likely to arise amongst particular classes of individuals in the population. For instance, inexperienced individuals may be more likely to try novel behaviors, as in several large migratory bird species 
340 where juveniles exhibit more variation in migratory routes than older individuals (Mueller et 341 al., 2013; Oppel et al., 2015; Vansteelant et al., 2017), particularly when there are few

342 experienced adults in the population (Mueller et al., 2013; Oppel et al., 2015). Although juveniles suffer from higher mortality, they are thought to be more likely to discover novel

344 adaptive routes. Conversely, amongst nonhuman primates, the inventors of novel behavior are usually more likely to be older, experienced individuals than youngsters (Reader \& Laland, 2001; Kendal et al, 2005), and more commonly low-ranking than dominants (Reader \& Laland, 2001). We characterize these patterns as manifestations of another type of developmental bias, which we call an origination bias, since they exhibit a bias in where the innovation will originate (see Table 1).

Biases arising from social learning

Animals frequently acquire knowledge and skills from conspecifics and heterospecifics, including adopting innovations devised by others. Here, the mechanism of transmission can influence the frequency of phenotypic variants in the next generation. This contrasts with the genetic inheritance system that follows the Hardy-Weinberg principle, implying that the mechanism of genetic transmission does not by itself cause changes in allele frequencies and, by implication, the frequency distribution of phenotypes. There are many mechanisms that cause exceptions to this principle, such as inter-species hybridization and the presence of standing genetic variation. This is important for evolution, because these processes can bias novel phenotypic variation towards adaptive variants (e.g. Rieseberg et al., 2003; Seehausen, 2014; Lai et al., 2019). Social learning is rarely considered in this context, perhaps because it is not expected to cause differences between alleles in the probability that they are being passed on to the offspring; it nonetheless clearly does affect the frequency distribution of phenotypes, and typically will do so in adaptive ways. Moreover, it also provides a mechanism for the inheritance of these phenotypes across generations.

Typically, animals do not copy at random, nor at all conceivable opportunities, nor simply copy the first individual that they see (Coussi-Korbel \& Fragaszy, 1995; Laland, 2004). Rather, animals copy highly selectively, deploying social learning strategies, which are transmission biases in copying (Boyd \& Richerson, 1985; Henrich \& McElreath, 2003, see Table 1). There are well-documented tendencies of animals to copy successful individuals and highpayoff behaviour preferentially, to conform to the majority behavior (known to be adaptive 
in spatially variable environments; Boyd \& Richerson, 1985), and also to copy more when

373 uncertain or when learning asocially would be costly or difficult (Laland, 2004; Rendell et al

374 2011; Kendal et al., 2018). Strategic copying is a general feature of animal social learning, whilst random copying is a comparatively rare special case (Hoppitt \& Laland, 2013). Almost all animal (including human) social learning is subject to a transmission bias.

Extensive experimental evidence has accumulated showing that animals exhibit a range of non-random copying strategies, often causing a transmission bias towards the more adaptive trait variants (Rendell et al. 2011; Kendal et al., 2018). A prime example is successbiased copying. For instance, red knots are more likely to join groups of foraging conspecifics that are successful at obtaining food (Bijleveld et al. 2015), whilst red-winged blackbirds copy feeding conspecifics except when they exhibit an aversive reaction to the food (Mason \& Reidinger 1982). Animals may also have a copying bias towards demonstrators that are more likely to be successful. For example, young female guppies have a preference for older over younger female models during mate-choice copying (Amlacher \& Dugatkin 2005). Similarly, nine-spined sticklebacks can monitor the foraging success of other fish through observation and subsequently select the richer of the alternative food patches, a mechanism that allows them to converge on the optimum (Coolen et al, 2003; Kendal et al., 2009). Whether animals copy, and whom they copy, can depend on their relative state of knowledge. For example, less-experienced pigeons are more likely to follow more-experienced pigeons than vice versa (Flack et al. 2012). Bats that are unsuccessful at locating food alone follow previously successful bats to feeding sites, using cues indicative of recent feeding, such as defecation (Wilkinson, 1992). Insects and birds too are known to copy the nest-site decisions of successful conspecifics and heterospecifics (Sarin \& Dukas, 2009; Pasqualone \& Davis, 2011; Seppanen et al 2011; Forsman \& Seppanen, 2011). One consequence of the existence of these transmission biases is that learned information does not spread randomly, but along specified (i.e. biased) pathways.

A second source of transmission bias in social learning stems from the fact that the learned traits an individual exhibits (unlike the individual's genes) are modified during the course of its development through experience. The net consequence is that the set of behavior patterns performed, and hence available to other individuals to copy, is not a random set but rather a biased set of high-performance, high-payoff behaviors. This mechanism leads to 'adaptive filtering' (Enquist \& Ghirlanda 2007), and a transmission bias 
to propagate adaptive knowledge. This adaptive bias associated with socially learned information was demonstrated by Rendell et al (2010), who found that social learning was highly adaptive under normal circumstances, where demonstrators chose to perform the highest-payoff option in their repertoire. But when the adaptive filtering of demonstrators was artificially switched off, such that demonstrators drew from their repertoire at random, social learning was no longer advantageous.

410 Teaching (i.e. behavior that functions to facilitate learning in another individual; 411 Hoppitt et al 2008; Thornton \& Raihani, 2010) is a third source of transmission bias. While 412 social learning is widespread amongst animals, teaching is rarer. Nonetheless, there is 413 evidence for teaching in a small number of species, including some ants, bees, birds and 414 meerkats, with other plausible but not yet experimentally demonstrated cases (Hoppitt et al 415 2008). Theory shows that it is only worth investing in teaching (by definition, a costly means 416 of information donation) if the adaptive advantage of the trait is large (Fogarty et al, 2011). 417 This conclusion is supported by experimental data. For example, honeybees actively 418 communicate potential nesting sites to the colony in autumn, but only after they have 419 decided that the nesting site is of appropriate quality (Seeley 1977; Seeley \& Buhrman 2001).

420 As a consequence, the more adaptive behavioral choice is more readily transmitted through 421 the colony.

422 Transmission biases on the part of the receiver, adaptive filtering by the information 423 transmitter, and teaching combine to reinforce the adaptive bias generated through asocial 424 learning. They ensure that 'good information' (supporting fitness-enhancing behavior) is far more likely to be propagated than 'bad information'. Social learning is applied flexibly, encompassing learning from both conspecifics and heterospecifics, which means that animals are not restricted to learning solely about those environmental features previously encountered by their lineage (e.g. established predators or foods). Animals can also learn about entirely novel stimuli or events, and devise appropriate responses to them (e.g. birds

430 learn to evade a novel predator; Davies \& Welbergen, 2009; Thorogood \& Davies, 2012). In 431 addition, learning can also generate opportunities for phenotypic change in the absence of 432 any immediate environmental change or stressor (such as when orangutans, Pongo 433 pygmaeus, proactively devise new food-processing techniques, social learning allows others 434 to access hitherto-unexploited foods, in this case palm heart; Russon, 2003). Thus, through 
learning, animals can generate adaptive responses to conditions without the prior evolution of dedicated traits with suitable reaction norms.

Various biases in the distribution of phenotypic variation that result from animal learning are summarized in Table 1, together with illustrative examples. These terms are neither mutually exclusive (for instance, historical, origin and transmission biases will also often be adaptive) nor is our classification designed to be exhaustive (plausibly, biases may exist that do not fit any of the categories in Table 1).

\section{The Evolutionary Consequences of Biased Variation Arising Through Learning}

Thus far, our focus has been on the learning processes responsible for the generation of biased phenotypic variation. In this section, we move on to consider the evolutionary consequences of biased variation arising through learning. We show that the production of nonrandom phenotypic through animal learning causes biases in the rate, dynamics and pattern of evolution (i.e. triggers developmentally biased evolutionary processes). In fact, learning can influence evolutionary processes in at least two separate ways: either through generating some phenotypic forms more readily than others (a variational bias) or through generating some environmental states more readily than others (a selective bias, a.k.a. 'niche construction').

\section{Learning affects evolutionary rates}

458 Theoretical work has established that learning can both speed up and slow down genetic evolution (Cavalli-Sforza \& Feldman 1981; Boyd \& Richerson 1985; Ancel 2000; Borenstein et al. 2006), consistent with the role of phenotypic plasticity in both driving and inhibiting genetic evolution (e.g. Chevin et al., 2010; Edelaar et al., 2017; Ghalambor et al., 2007; Price at al., 2003). Learning has an advantageous effect on adaptation in relatively quickly changing environments, allowing individuals to acclimate to changes that cannot be tracked by selection of genes (Cavalli-Sforza \& Feldman 1981; Boyd \& Richerson 1985; Todd 1991; Aoki \& Feldman, 2014). The benefits of learning in stationary or slowly changing environments are more complex. Hinton and Nowlan (1987) suggested that learning could accelerate evolution 
in a static environment by helping genotypes to locate otherwise difficult-to-find fitness peaks. However, learning can also weaken selection by reducing phenotypic differences between genotypes (Anderson 1995; Ancel 2000; Frank 2011). These seemingly conflicting results follow from different theoretical assumptions (Borenstein et al. 2006; Paenke et al. 2007; Frank 2011). The emerging consensus is that individual learning typically slows evolution in static unimodal fitness landscapes, but typically accelerates evolution in dynamic or static multimodal fitness landscapes. In the latter case, the existence of multiple optima usually slows down evolution as populations get trapped on suboptimal fitness peaks. By generating adaptive variation and thereby smoothing the fitness landscape, learning increases the likelihood of a directly increasing path of fitness to the global optimum (Borenstein et al. 2006; Mills and Watson 2006; Frank 2011).

Learning can generate 'plasticity first' evolution

The 'plasticity first hypothesis' is "a mechanism of adaptive evolution in which environmental perturbation leads, via phenotypic plasticity, to ... a novel developmental variant (i.e., trait) that ... is subsequently refined through 'genetic accommodation'" (Levis \& Pfennig, 2016, p564). Here, 'genetic accommodation' means the refinement or stabilization of the trait through selection of underlying genetic variation. Where learning accelerates evolution, phenotypic change (a.k.a. 'phenotypic accommodation') precedes, and then facilitates, genetic adaptation by modifying selection on genetic variation (West-Eberhard, 2003; Levis \& Pfennig, 2016). Conversely, when sources of learning are reliably present (e.g. the availability of a parent when a chick hatches), social learning can buffer selection on genetic variation that would otherwise lead to genetic adaptation, as selection cannot favor a trait that compensates for the loss of developmental input that is reliably present (Griffiths 2002). However, in many cases this buffering will not be perfect, and hence will not preclude selection of alleles that increase the probability of producing, or the performance of, the learned phenotype, a form of genetic accommodation known as 'genetic assimilation' (WestEberhard, 2003). Indeed, (particularly stochastic) learning can facilitate genetic adaptation through producing adaptively biased phenotypic variation that changes the selection on genotypes (Borenstein et al. 2006).

There is empirical evidence that learning can generate plasticity first evolution (Whitehead et al, 2019). For instance, killer whale (Orcinus orca) populations exhibit culturally 
transmitted specializations on particular prey resources (e.g. fish, dolphins, pinnipeds). These dietary traditions have favored population-specific genes influencing morphology and digestion, giving rise to different killer whale "ecotypes" (Foote et al., 2016; Hoelzel \& Moura, 2016). Population-genomic studies confirm that these lineages have diverged genetically, and that functional genes associated with digestion differ between ecotypes, suggesting that this is an instance of genetic assimilation (Foote et al., 2016; Hoelzel \& Moura, 2016). Seemingly, the ecotypes arose through culturally mediated specialization in matrilineal groups, which later developed reproductive barriers (Riesch et al 2012). Here, learning and social transmission appears to have triggered the evolution of multiple lineages considered to be undergoing speciation, influencing the direction of adaptive evolution.

Social learning can also trigger genetic adaptation in other traits (Whitehead et al, 2019). For instance, in some fruit flies, fishes, birds and mammals, the choice of mating partner is influenced by the mate-choice decisions of other individuals (mate-choice copying). This propagates mating preferences over short periods, such as a season, yet experimental data and population-genetic models demonstrate that it can strongly influence the sexual selection of male traits (Gibson et al., 1991; Kirkpatrick \& Dugatkin, 1994; Nöbel et al., 2018). Birdsong provides another illustration of how animal culture can be consequential for genetic evolution, affecting patterns of migration and assortative mating, and facilitating speciation (Beltman et al, 2003; Lachman \& Slater 1999). There is evidence for reed warbler learning driving the evolution of plumage patterns in cuckoos (Davies \& Welbergen, 2009; Thorogood \& Davies, 2012), and for social learning reducing genetic diversity in socially structured whale populations (Whitehead, 1998). Finally, extensive empirical evidence now implicates learning in mate choice, sexual selection, and reproductive isolation, where experimental studies clearly show that learning imposes biases on signal evolution (ten Cate \& Rowe, 2007; Verzijden et al., 2012). Hence, the theoretical expectation of genetic accommodation and genetic assimilation in response to animal learning is supported by a small and growing number of studies.

In these examples, learning is not just changing the rate of evolution but co-directing the outcome. It was the culturally transmitted dietary tradition of each killer whale population that caused the natural selection of genes for a morphology and digestive physiology that matches their learned dietary habits. Similar points can be made with respect to the mate choice, bird song, and plumage evolution examples. 
531 bringing about physical changes in environments, or through learned habitat choice. Over the

532 past 50,000 years, humans have spread from Africa around the globe, begun to exploit agriculture, witnessed rapid increases in densities as a direct consequence, domesticated

534 hundreds of species of plants and animals and, by keeping animals, experienced a new proximity to animal pathogens. Each of these events represents a major transformation in human selection pressures, recognized though substantive genetic change in human populations, and each is a self-induced change in environmental conditions (Laland et al, 2010). Humans have modified selection through their learning and culture, for instance by dispersing into new environments with different climatic regimes, by devising agricultural practices or domesticating livestock, and causing extinctions and dramatic shifts in community structure (Boivin et al, 2016). It is now well-established that dairy farming created the selection pressure that led to the spread of alleles for adult lactase persistence (Gerbault et al, 2011). Similarly, agricultural practices, such as cultivating yams, appear to have inadvertently promoted the spread of malaria in some West African populations, leading to the selection of the $\mathrm{HbS}$ allele which confers some resistance to malaria in the heterozygote form, but leads to Sickle-cell anaemia in homozygotes (Durham, 1991). The same practices appear also to have favored high copy number of the salivary amylase (AMY1) gene that facilitate the breakdown of the excess starch in agricultural diets (Perry et al, 2007). Again, such examples illustrate how learning can affect evolutionary outcomes, and not just rates. Producing and consuming milk and alcohol has selected for alleles for adult lactose absorption and alcohol dehydrogenase, whilst the agricultural practices that led to greater consumption of starch, protein, lipids and phosphate have selected for alleles that metabolize these foods (Laland et al 2010). Given that both niche construction and learning are ubiquitous in animals, it would seem highly likely that the learned environmental modification of other animals has similar consequences, although well-researched examples are rare.

Learned human activities are also driving evolutionary responses in other animals. Recent studies have demonstrated strong phenotypic changes in organisms in response to urban and other anthropogenic environments, ranging from supplemental feeding affecting beak shape in garden birds, to earthworms and insects evolving tolerance of pollutants (Palkovacs et al, 2012; Alberti, 2015; Alberti et al, 2017; Sullivan et al, 2017). Anthropogenic change studies suggest plasticity is important to evolutionary responses (Snell-Rood et al, 
2018; Fox et al, 2019), and the field could benefit from greater consideration of the role played by animal learning in these adaptive responses.

Learning can generate 'adaptation' without natural selection

566 It is often claimed that natural selection is the only process that can systematically lead to increments in fitness across generations, but adaptive evolution can also result from phenotypic plasticity, habitat choice and niche construction (Edelaar \& Bolnick, 2019). This is an important point, since it is widely, and mistakenly, believed that incremental improvements in a trait over generations, with corresponding enhancements in fitness, can only arise through the natural selection of genetic variation.

Experimental evidence reveals that social learning (a form of adaptive phenotypic plasticity) can cause offspring fitness to be higher than that of their parents, even in novel habitats. This is, at least to some extent, recognized for humans where, for example, agricultural advances (irrigation methods, fertilizers, breeding programs, insecticides, etc) have repeatedly underpinned population growth (i.e. increased absolute fitness). However, evidence is starting to emerge for similar processes operating in other animals. For instance, Jesmer et al (2018) showed that bighorn sheep and moose adjust to novel environments in the course of several generations, through a process of learning and cultural transmission. These animals generally migrate through exploiting the high-quality forage manifest in "green-wave surfing" (van der Graaf et al. 2006), which requires possessing the requisite knowledge of where and when to find high-quality food; a typical needle-in-a-haystack problem. The study shows that after translocation to a novel environment, the animals do not show their typical migratory behavior. Apparently, past natural selection did not enable individuals to find the optimal foraging strategy in a single lifetime. Rather, the study shows an iterative increase over generations in the fraction of translocated populations that migrate, and that - due to these movements - their whereabouts increasingly overlaps with

588 the phenology of suitable habitat. The bighorn sheep acquire and accumulate this 'adaptation' to a novel habitat not through natural selection of genes, but through learning.

590 Seemingly, individual learning allows each generation to exploit high-quality forage more 591 effectively than their parental generation, and social learning allows these iterative 592 improvements to be transmitted to the rest of the group, including the next generation. Here 
improvements in the adaptive fit between individuals and their environment accumulate over generations.

The semi-natural experiment of translocated sheep is unique in its temporal and spatial scale, but similar processes likely operate widely. Sasaki \& Biro (2017) demonstrate the process of incremental increase in movement efficiency (which in the wild should correlate with fitness) amongst gps-tagged homing pigeons, which arises through 'cumulative culture'. Similarly, sticklebacks have been found to exhibit a hill-climbing learning strategy of selectively adopting the food-patch choices of fish more successful than them (Coolen et al, 2003; Kendal et al., 2009). While these studies do not demonstrate increases in fitness across generations, they do show that adaptive phenotypic plasticity mechanisms exist that mimic 'adaptation' without the natural selection of genetic variation.

The evolutionary relevance of such mechanisms will not go unnoticed to those familiar with the Price equation. In addition to the selective term, the Price equation contains a term that captures whether the next offspring systematically differ from their parents, which can be rendered positive by adaptive phenotypic plasticity (Edelaar \& Bolnick, 2019). Many open questions remain as to the extent of such phenomena among different taxa and in the wild, but there can be little doubt that they have far-reaching consequences for evolution (Berdahl et al. 2018; Edelaar \& Bolnick, 2019; Brakes et al., 2019).

611

\section{Learning can help explain the existence of maladaptation}

613 Without gainsaying the general conclusion that learning typically generates adaptive 614 phenotypic variation, there are restricted and reasonably well-understood circumstances in 615 which learning can generate, propagate and maintain maladaptive behavior. It is commonly 616 assumed that natural selection will shape organisms to reflect environmental conditions, but 617 cultural transmission can allow animal behavior to become partially disconnected from their 618 environments. For instance, Bluehead wrasse Thalassoma bifasciatum mating sites cannot be 619 predicted from knowledge of environmental resource distributions (Warner, 1988, 1990). 620 Rather, removal and replacement experiments demonstrate that mating sites are maintained 621 as traditions, with young fish and newcomers adopting the mating sites of residents (similar 622 findings are observed in French grunts; Helfman \& Schultz, 1984). Under restricted 623 circumstances arbitrary and even maladaptive information can spread, or initially-but-no624 longer-adaptive traits can be preserved (Richerson \& Boyd, 2005). Traditions are maintained 
as Nash equilibria, in which it rarely pays any individual to abandon the tradition unilaterally;

626 each is forced to do what others are doing, leaving populations locked into conventions that

627 track changing environments only slowly. In animals that aggregate for protection, like 628 shoaling fishes, taking the same route as others to a resource, such as a food site, offers 629 fitness benefits even when the route is sub-optimal, since going it alone is dangerous (Laland 630 \& Williams 1998). This behavior, and other conformist tendencies (Day et al, 2001), help explain the traditions observed in natural fish populations. In the case of the wrasse, initially 632 adaptive pathways were rendered suboptimal by environmental change, but the population 633 remained locked into a difficult-to-change convention. Another case is informational cascades, where individuals base behavioral decisions on prior decisions of others (Giraldeau et al. 2002). For instance, among lekking sage grouse Centrocercus urophasianus, the decisions of females using social information to decide with whom to mate were less closely correlated with male traits indicating quality than were the decisions of females making their own judgments about males (Gibson et al. 1991). These instances are a form of historical bias, although distinct from genetically evolved biases.

Theoretical studies suggest further ways by which learning can generate maladaptation. As described above, reinforcement learning typically comprises an exploratory search (information gathering) followed by decision-making (information exploitation). However, the two stages are not mutually exclusive: rather reinforcement 644 learning often entails both processes operating simultaneously, or in repeated sequence, 645 allowing animals to gain information from a decision-making experience and to refine their decision in the light of updated knowledge, in an iterative manner (Sutton \& Barto, 1998). As a consequence, biases in decision-making can bias the acquisition of knowledge, and viceversa (Hertwig \& Erev, 2009; March, 1996). This sequential, path-dependent nature of animal learning can be a crucial determinant of the behavior manifest in the population. For instance, March (1996) demonstrated formally how animal learning could lead to risk-averse behavior when its expected reward was lower than a risky alternative. Animals must strike a balance between exploration and exploitation, which typically leads them to reduce the rate of sampling of apparently inferior options. As a result, risky alternatives, which usually give a poor reward but occasionally give a very good reward, are interpreted as worse than they actually are, leading individuals to over-exploit safe alternatives (March, 1996; Denrell, 2007; empirical examples of learning-induced risk aversion are reviewed in Weber et al. 2004, whilst 
similar 'peak shift' phenomena are described by ten Cate \& Rowe, 2007). Outside of humans, cases of the cultural transmission or maintenance of maladaptive behavior appear rare: more commonly, social learning strategies allow individuals to revisit superior options, even despite repeated personal failures, circumventing potentially maladaptive risk aversion (Rendell et al, 2010; Arbilly et al. 2011).

662

\section{CONCLUSIONS}

664 Developmental biases remain contentious in evolutionary biology, in part because of the claim that developmental processes may impose direction on adaptive evolution and/or account for adaptation - a claim that ostensibly challenges the widespread belief that natural selection does all of the explanatory work in accounting for adaptive evolution (Maynard Smith et al, 1985; Arthur, 2004; Brakefield 2006; Laland et al 2015; Uller et al, 2018). Given that developmental processes themselves evolve, it is perhaps tempting to respond to such claims by regarding the bias as itself a product of natural selection, a stance that might (at least in some researcher's eyes) restore natural selection's privileged status. However, at least in the case of developmental biases that result from learning, such a response appears inadequate.

Whilst the general capacity to learn has clearly evolved through natural selection, the above literature leaves no doubt that the content of learning (the precise associations formed, and the behavioral phenotypes that result) is rarely, if ever, specified by ancestral selection. As documented above, animals are able to learn to exploit foods, or evade threats, even when they are novel and have not been encountered by the lineage, often acquiring them from other species. Moreover, such learning is frequently evolutionarily consequential. In such instances, the traditional line that ancestral natural selection favored genes or genotypes with reaction norms that allow animals to adjust their phenotypes to environmental inputs appears overly simplistic. In learning, ancestral selection has conferred on animals an unusually rich form of plasticity that appears to possess some level of autonomy to generate 'adaptive fit' within an individual as a result of its experience, through an ontogenetic selective process that in many respects resembles natural selection (Plotkin 1994; Snell-Rood et al 2018).

Above we present clear evidence that (i) individual learning commonly allows animals to generate novel and adaptively biased behavior tuned to the local environment, (ii) social 
learning further biases the propagation of these phenotypic improvements to other

690 individuals, (iii) this learning can modify selection and affect evolutionary dynamics, and (iv)

691 culture sometimes allows animals to improve mean fitness iteratively across generations in a process that resembles 'adaptation'. While these observations are well-recognized within the animal learning literature, they remain poorly appreciated within the evolutionary biology community. For instance, in an otherwise admirable book, Bonduriansky and Day (2018) claim that "only cognitively sophisticated animals" could learn adaptive solutions to novel circumstances, and suggest that maladaptive behavior would spread just as readily as accessing a novel food - claims that are badly out of touch with the literature. There is now extensive data showing that, through learning, a very broad range of species of animals regularly invent and propagate adaptive behavior that introduces novelty into phenotype space.

The significance of these findings may be profound. Recently, the suggestion (associated with the extended evolutionary synthesis) that "novel phenotypic variants will frequently be directional and functional" (Laland et al, 2015, p10) excited considerable contention (e.g. Charlesworth et al, 2017). Yet we suspect to readers familiar with the above referenced literature on animal learning, the assertion would not appear unreasonable. Almost all animal innovation, and almost all socially transmitted knowledge and skills, are likely to be adaptive, and those cases that are not can be predicted a priori. Animal learning is an important addition to a range of phenomena that are now broadly accepted to undermine the classic view that adaptation arises solely from natural selection acting on random genetic variation.

The reason that learning evolved to become an unusually rich form of adaptive plasticity is precisely because of the benefits to animals of being able to response appropriately to unanticipated eventualities (Plotkin, 1994; Staddon, 2016). The term

714 'evolvability' attempts to capture the capacity of a system for adaptive evolution. There are diverse definitions of evolvability, many inherently assuming that adaptive evolution requires genetic change. However, we embrace the broader definition provided by Kirschner \&

717 Gerhart (1998) - "an organism's capacity to generate heritable phenotypic variation" - in the 718 context of which it is possible to recognize how learning (a source of novel, frequently 719 heritable, phenotypic variation) contributes to evolvability. Through behavioral innovation and social learning, animals can adjust to environments phenotypically, sometimes buffering 
genetic responses, but perhaps more commonly triggering genetic accommodation. The impact of learning on evolvability is further suggested by recent studies showing a robust relationship between innovativeness and speciosity in birds (Nicolakkis et al, 2003; Sol et al 2005; Lefebvre et al., 2016). These data reinforce the aforementioned evidence that learning can impose direction on adaptive evolution, affecting evolutionary rates, and influencing the probability of populations reaching global optimum.

There are many open questions ripe for investigation. For instance, do biases that arise through learning differ from other developmental biases, for instance, in the level of integration or diversity of phenotypes generated? Are there different patterns of bias associated with individual and social learning? Will success-based copying generate more rapid convergence through genetic accommodation on fitness peaks than conformist social learning, which is prone to historical lags? Further investigation is required, but there is already sufficient data to suggest that phenotypic accommodation through learning may be common, rapid and powerful, particularly in vertebrates, and that developmentally biased evolutionary processes resulting from learning may be a truly fundamental feature of animal evolution.

\section{ACKNOWLEDGEMENTS}

Research supported in part by a grant from the John Templeton Foundation to KNL ("Putting the extended evolutionary synthesis to the test", ref 60501), by Japan Society for the Promotion of Science KAKENHI to WT (ref 17J01559), and a grant from the Netherlands Organization for Scientific Research to TO (ref 019.172EN.011).

\section{REFERENCES}

Alberti, M. (2015). Eco-evolutionary dynamics in an urbanizing planet. Trends in Ecology \& Evolution, 30, 114-126.

Alberti, M., Correa, C., Marzluff, J.M., Hendry, A.P., Palkovacs, E.P., Gotanda, K.M., ... \& Zhou, Y. (2017). Global urban signatures of phenotypic change in animal and plant populations. Proceedings of the National Academy of Sciences, 201606034. 
Allen, J., Weinrich, M., Hoppitt, W. \& Rendell, L. (2013) Network-based diffusion analysis reveals cultural transmission of lobtail feeding in humpback whales. Science 340: 485488.

Amlacher, J. \& Dugatkin, L.A. (2005) Preference for older over younger models during matechoice copying in young guppies. Ethology Ecology \& Evolution, 17: 161-169

Ancel, L. (2000). Undermining the Baldwin expediting effect: does phenotypic plasticity accelerate evolution? Theor. Popul. Biol. 58: 207-319.

Anderson, R. (1995). Learning and evolution: a quantitative genetics approach. J. Theor. Biol. 175: 89-101.

Aoki K \& Feldman MW (2014) Evolution of learning strategies in temporally and spatially variable environments: A review of theory. Theor. Pop. Biol. 91: 3-19

Arbilly M, Motro U, Feldman MW, \& Lotem A (2011) Evolution of social learning when high expected payoffs are associated with high risk of failure. J. Roy. Soc. Interface, 8: 16041615.

Arthur, W. (2004) The effect of development on the direction of evolution: toward a twentyfirst century consensus. Evol. Dev. 6: 282-288

Beltman, J., Haccou, P. \& Ten Cate, C. (2003) The impact of learning foster species' song on the evolution of specialist avian brood parasitism. Behav. Ecol. 14: 917-923.

Berdahl, A.M., Kao, A.B., Flack, A., Westley, P.A.H., Codling, E.A., Couzin, I.D., Dell, A.I. \& Biro, D. (2018) Collective animal navigation and migratory culture: from theoretical models to empirical evidence. Philosophical Transactions of the Royal Society B: Biological Sciences, 373: 20170009.

Bijleveld, A.I., van Gils, J.A., Jouta, J. \& Piersma, T. (2015) Benefits of foraging in small groups: an experimental study on public information use in red knots Calidris canutus. Behavioural Processes, 117: 74-81.

Boivin NL, Zeder MA, Fuller DQ et al (2016) Ecological consequences of human niche construction: examining long-term anthropogenic shaping of global species distributions. Proc. Natl. Acad. Sci. USA 113(23): 6388-96

Bolhuis, J. J. \& MacPhail, E. M. (2001). A critique of the neuroecology of learning and memory. Trends in Cognitive Sciences, 5, 426-433.

Bonduriansky R \& Day T (2018) Extended Heredity. Princeton University Press. 
Borenstein, E., I. Meilijson, and E. Ruppin. (2006). The effect of phenotypic plasticity on evolution in multipeaked fitness landscapes. Journal of Evolutionary Biology 19:15551570.

Boyd R \& Richerson PJ (1985). Culture and the Evolutionary Process. Chicago University Press. Brakefield, P. M. (2006) Evo-devo and constraints on selection. Trends Ecol. Evol. 21: 362368.

Brakes P et al. (2019) Animal cultures matter for conservation. Science 363(6431): 1032-4

Breland K \& Breland M (1961). The misbehavior of organisms. Am. Psychol. 16: 661-4

Cavalli-Sforza LL \& Feldman MW (1981). Cultural Transmission and Evolution. Princeton University Press

Charlesworth, D., N. H. Barton \& B. Charlesworth (2017) The sources of adaptive variation. Proceedings of the Royal Society B-Biological Sciences 284: 20162864.

Chevin, L. M., Lande, R., \& Mace, G. M. (2010). Adaptation, plasticity, and extinction in a changing environment: towards a predictive theory. PLoS biology, 8(4), e1000357.

Chivers, D. P. \& Smith, R. J. F. (1995) Chemical recognition of risky habitats is culturally transmitted among flathead minnows, Pimephales promelas (Osteichthyes, Cyprinidae). Ethology 99: 286-296.

Coolen, I., Day, R.L. \& Laland, K.N. (2003). Species difference in adaptive use of public information in sticklebacks. Proceedings of the Royal Society London B 270: 24132419.

Coussi-Korbel, S. and Fragaszy, D. M. (1995) On the relation between social dynamics and social learning. Anim. Behav. 50(6): 1441-53.

Curio, E. (1988). Cultural transmission of enemy recognition by birds. In: Social Learning: Psychological and Biological Perspectives, B. G. Galef and T. R. Zentall, Eds. Hillsdale, NJ: Erlbaum. Pp. 75-97.

Davies, N. B. \& Welbergen, J. A. (2009) Social transmission of a host defense against cuckoo parasitism. Science 324: 1318-1320.

Day, R., MacDonald, T., Brown, C., Laland, K.N. \& Reader, S.M. (2001). Interactions between shoal size and conformity in guppy social foraging. Animal Behaviour 62: 917-925.

Denrell J. (2007). Adaptive Learning and Risk Taking. Psychological Review. 114: 177-187.

Dickinson A (1980) Contemporary animal learning theory. Cambridge University Press

Dukas R \& Ratcliffe JM (eds.) (2009) Cognitive Ecology II.University of Chicago Press. 
Durham WH (1991) Coevolution. Genes, Culture and Human Diversity. Stanford University Press.

Edelaar P \& Bolnick DI (2019) Appreciating the multiple processes increasing individual or population fitness. Trends Ecol. Evol. https://doi.org/10.1016/j.tree.2019.02.001

Edelaar, P., Jovani, R., \& Gomez-Mestre, I. (2017). Should I change or should I go? Phenotypic plasticity and matching habitat choice in the adaptation to environmental heterogeneity. The American Naturalist, 190(4), 506-520.

Enquist, M. \& Ghirlanda, S. (2007) Evolution of social learning does not explain the origin of human cumulative culture. Journal of Theoretical Biology, 246: 129-135.

Fogarty, L, Strimling P. \& Laland K.N. (2011). The evolution of teaching. Evolution. 65: 27602770.

Foote, A. D. et al. (2016) Genome-culture coevolution promotes rapid divergence of killer whale ecotypes. Nat. Commun. 7: 11693

Forsman, J. and Seppanen, J. (2011). Learning what (not) to do: testing rejection and copying of simulated hetrospecific behavioural traita. Anim. Behav. 81: 879-883.

Fox RJ, Donelson JM, Schunter C, Ravasi T, Gaita' n-Espitia JD. 2019 Beyond buying time: the role of plasticity in phenotypic adaptation to rapid environmental change. Phil. Trans. R. Soc. B 374: 20180174. http://dx.doi.org/10.1098/rstb.2018.0174

Frank SA (2011). Natural selection II. Developmental variability and evolutionary rate. J. Ev. Biol. 24: 2310-2320.

Garcia, J. \& Koelling, R. A. (1966). Prolonged relation of cue to consequence in avoidance learning. Psychonomic Science, 4: 123-124.

Gerbault, P., A. Liebert, Y. Itan, A. Powell, M. Currat, J. Burger, D. M. Swallow, and M. G. Thomas. (2011). Evolution of lactase persistence: an example of human niche construction. Philosophical Transactions of the Royal Society B 366:863-877. adaptive phenotypic plasticity and the potential for contemporary adaptation in new environments. Functional ecology, 21(3), 394-407. 
Gibson, R. M., Bradbury, J. W. \& Vehrencamp, S. L. (1991) Mate choice in lekking sage grouse revisited: the roles of vocal display, female site fidelity, and copying. Behav. Ecol. 2: 165-180.

Giraldeau, L. A., Valone, T. J. and Templeton, J. J. (2002). Potential disadvantages of using socially acquired information. Phil. Trans. R. Soc. Lond. B 357: 1559-1566.

Goodall, J. (1986) The chimpanzees of Gombe: patterns of behavior. Harvard University Press, Cambridge, MA.

Griffiths, P.E. (2002) What Is Innateness? The Monist, 85, 70-85.

Helfman G. S., Schultz, E. T. (1984). Social transmission of behavioural traditions in a coral reef fish. Anim. Behav. 32: 379-384.

Henrich, J. and McElreath, R. (2003). The evolution of cultural evolution. Evol. Anthropol. 12: $123-135$.

Hertwig R \& Erev I. (2009). The description-experience gap in risky choice. Trends Cog. Sci. 13:517-523.

Heyes, C.M. (1994) Social learning in animals: categories and mechanisms. Biological Reviews, 69: $207-231$.

Hinde RA (1982) Ethology. Glasgow. Fontana.

Hinde RA \& Stephenson-Hinde (1973) Constraints on learning. Limitations and Predispositions. Academic Press

Hinton GE \& Nowlan SJ (1987) How learning can guide evolution. Complex Systems 1: 495502.

Hoelzel, A. \& Moura, A. (2016) Killer whales differentiating in geographic sympatry facilitated by divergent behavioural traditions. Heredity 117: 481-482.

Hoppitt, W. \& Laland, K.N. (2013) Social learning: an introduction to mechanisms, methods and models. Princeton University Press, Princeton, NJ.

Hoppitt, W.J.E., Brown, G.R., Kendal, R., Rendell, L., Thornton, A., Webster, M.M. \& Laland, K.N. (2008) Lessons from animal teaching. Trends in Ecology \& Evolution, 23: 486-493.

Huey, R. B., Hertz, P. E., \& Sinervo, B. (2003). Behavioral drive versus behavioral inertia in evolution: a null model approach. The American Naturalist, 161(3), 357-366.

Jesmer BR et al (2018) Is ungulate migration culturally transmitted? Evidence of social learning from translocated animals. Science 361: 1023-5 
Kamil AC (1983). Optimal foraging theory and the psychology of learning. American Zoologist 23: $291-302$

Kawai, M. (1965). Newly-acquired pre-cultral behavior of the natural troop of Japanese monkeys on Koshima islet. Primates 6: 1-30.

Kendal, R.L., Coe, R.L. \& Laland, K.N. (2005). Age differences in neophilia, exploration and innovation in family groups of Callitrichid monkeys. American Journal of Primatology 66: 167-188.

Kendal, J.R., Rendell, L., Pike, T.W. \& Laland, K.N. (2009). Nine-spined sticklebacks deploy a hill-climbing social learning strategy. Behavioural Ecology 20: 238-244.

Kendal RL, Boogert NJ, Rendell L, Laland KN, Webster M \& Jones PL. (2018) Social learning strategies: bridge-building between fields. Trends in Cognitive Sciences 22(7):651-665

Kirschner M \& Gerhardt J 1998. Evolvability. Proc. Natl. Acad. Sci. USA 95(15): 8420-7

Kirkpatrick, M. and L. A. Dugatkin. (1994). Sexual selection and the evolutionary effects of copying mate choice. Behav. Ecol. Sociobiol. 34: 443-449.

Kirkpatrick K \& Hall G (2004) Learning and Memory. In Bolhuis JJ \& Giraldeau LA (eds) The Behavior of Animals: Mechanisms, Function, and Evolution. Blackwell.

Krebs, J. R., A. Kacelnik, and P. Taylor. (1978). Test of optimal sampling by foraging great tits. Nature 275:27-31.

Lachlan, R. F. and Slater, P. J. B. (1999). The maintenance of vocal learning by gene-culture interaction: the cultural trap hypothesis. Proc. R. Soc. Lond, B 266: 701-706.

Lai, Y.-T., Yeung, C.K.L., Omland, K.E., Pang, E.-L., Hao, Y., Liao, B.-Y., Cao, H.-F., Zhang, B.-W., Yeh, C.-F., Hung, C.-M., Hung, H.-Y., Yang, M.-Y., Liang, W., Hsu, Y.-C., Yao, C.-T., Dong, L., Lin, K., and Li, S.-H. (2019) Standing genetic variation as the predominant source for adaptation of a songbird. Proceedings of the National Academy of Sciences 116: 21522157.

Laland, K.N. (2004). Social learning strategies. Special edition of Learning and Behavior on Studies of Social Learning and Imitation. Galef, B.G. Jr. \& Heyes, C.M. (eds). 32: 4-14.

Laland, K.N. \& Williams, K. (1998). Social transmission of maladaptive information in the guppy. Behavioural Ecology 9: 493-499.

Laland, K.N., Odling-Smee, F.J. \& Myles, S. (2010). How culture has shaped the human genome: Bringing genetics and the human sciences together. Nature Reviews Genetics 11: $137-148$. 
Laland KN, Uller T, Feldman MW, Sterelny K, Müller GB, Moczek A, Jablonka E \& Odling-Smee FJ (2015) The extended evolutionary synthesis: its structure, assumptions and predictions. Proc R Soc B 282: 20151019.

Laland KN, Odling-Smee J \& Feldman MW. (In Press) Understanding niche construction as an evolutionary process. In: Uller T \& Laland KN (eds.) Evolutionary Causation. Biological and Philosophical Reflections. MIT Press: Cambridge, Mass.

Lefebvre, L., P. Whittle, E. Lascaris, and A. Finkelstein. (1997). Feeding innovations and forebrain size in birds. Animal Behaviour 53:549-560.

Lefebvre, L., S. Ducatez, and J. N. Audet. (2016). Feeding innovations in a nested phylogeny of Neotropical passerines. Philosophical Transactions of the Royal Society of London B, 371: 20150188.

Levis, N. A. \& Pfennig, D. W. (2016) Evaluating 'plasticity-first' evolution in nature: key criteria and empirical approaches. Tr. Ecol. Evol. 31: 563-574.

Love AC (ed) (2015) Conceptual Change in Biology. Springer.

Mackintosh N (1974) The psychology of animal learning. Academic Press

March, J. G. (1996). Learning to be risk averse. Psychological Review, 103, 309-319.

Mason, J.R. \& Reidinger, R.F. (1982) Observational learning of food aversions in red-winged blackbirds (Agelaius phoeniceus). Auk, 99: 548-554.

Maynard-Smith, J., R. Burian, S. Kauffman, P. Alberch, J. Campbell et al., (1985) Developmental constraints and evolution. Q. Rev. Biol. 60: 265-287.

Maynard-Smith J. (1987) When learning guides evolution. Nature 329: 761-2

Mills, R., and R. A. Watson (2006) On crossing fitness valleys with the Baldwin effect, pp. 493499 in Proceedings of the Tenth International Conference on the Simulation and Synthesis of Living Systems. MIT Press, Cambridge, MA.

Mineka, S. and Cook, M. (1988). Social learning and the acquisition of snake fear in monkeys. In: Social Learning: Psychological and Biological Perspectives, B. G. Galef and T. R. Zentall, Eds. Hillsdale, NJ: Lawrence Erlbaum. Pp. 51-73.

Moczek AP (2008). On the origins of novelty in development and evolution. BioEssays 30(5): $432-47$

Moczek AP, Sears KE, Stollewerk et al. (2015) The significance and scope of evolutionary developmental biology: a vision for the $21^{\text {st }}$ century. Evolution \& Development. $17(3)$ : $198-219$ 
Mueller T, O'Hara RB, Converse SJ, Urbanek RP, Fagan WF (2013) Social learning of migratory performance. Science 341:999-1002.

Muñoz, M. M., \& Losos, J. B. (2018). Thermoregulatory behavior simultaneously promotes and forestalls evolution in a tropical lizard. The American Naturalist, 191(1), E15-E26.

Nicolakakis, N., D. Sol, and L. Lefebvre. (2003). Behavioral exibility predicts species richness in birds, but not extinction risk. Animal Behaviour 65:445-452.

Nöbel S, Allain M, Isabel G, Danchin E. (2018) Mate copying in Drosophila melanogaster males. Anim Behav . 141:9-15.

Odling-Smee, F.J., Laland, K.N. \& Feldman, M.W. (2003). Niche Construction. The Neglected Process in Evolution. Monographs in Population Biology 37. Princeton University Press.

Oppel, S., Dobrev, V., Arkumarev, V., Saravia, V., Bounas, A., Kret, E., Velevski, M., Stoychev, S. \& Nikolov, S.C. (2015) High juvenile mortality during migration in a declining population of a long-distance migratory raptor. Ibis, 157, 545-557.

Paenke, I., B. Sendhoff, and T. J. Kawecki, (2007) Influence of plasticity and learning on evolution under directional selection. Am. Nat. 170: E47-E58.

Palkovacs, E. P., Kinnison, M. T., Correa, C., Dalton, C. M. \& Hendry, A. P. (2012). Fates beyond traits: ecological consequences of human-induced trait change. Evolutionary Applications, 5, 183-191.

Pasqualone, A. A. and Davis, J. M. (2011). The use of conspecific phenotypic states as information during reproductive decisions. Anim. Behav. 82: 281-4

Perry, G. H., N. J. Dominy, K. G. Claw, A. S. Lee, H. Fiegler, R. Redon, J. Werner, et al. (2007). Diet and the evolution of human amylase gene copy number variation. Nature Genetics 39:1256-1260.

Plotkin HC (1994) Darwin machines and the nature of knowledge. Penguin

Price, T. D., Qvarnström, A., \& Irwin, D. E. (2003). The role of phenotypic plasticity in driving genetic evolution. Proceedings of the Royal Society of London. Series B: Biological Sciences, 270(1523), 1433-1440.

Pulliam H \& Dunford C (1980) Programmed to Learn. Columbia University Press.

Reader SM, Laland KN. (2001) Primate innovation: sex, age and social rank differences. Int. J. Primatol. 22, 787-805.

Reader, S.M. \& Laland, K.N. (2002). Social intelligence, innovation and enhanced brain size in primates. Proceedings of the National Academy of Sciences USA 99: 4436-4441. 
Reader SM, Laland KN. (2003) Animal innovation. Oxford, UK: Oxford University Press.

Reader SM, Flynn E, Morand-Ferron J \& Laland KN (2016) Innovation in animals and humans: understanding the origins and development of novel and creative behaviour. Phil. Trans. R. Soc. B Vol 371: 1690

Rendell, L., Boyd, R., Cownden, D., Enquist, M., Eriksson, K., Feldman, M.W., Fogarty, L., Ghirlanda, S., Lillicrap, T. \& Laland, K.N. (2010) Why copy others? Insights from the social learning strategies tournament. Science, 328: 208-213.

Rendell, L., Fogarty, L., Hoppitt, W.J.E., Morgan, T.J.H., Webster, M.M. \& Laland, K.N. (2011) Cognitive culture: theoretical and empirical insights into social learning strategies. Trends in Cognitive Sciences, 15, 68-76.

Rescorla, RA (1988) Pavlovian Conditioning. Am. Psychol 43(3): 151-160

Rescorla, R. A. \& Wagner, A. R. (1972). A theory of Pavlovian conditioning: Variations in the effectiveness of reinforcement and nonreinforcement. In A. H. Black \& W. F. Prokasy (Eds.), Classical Conditioning II: Current Research and Theory (pp. 64-99). New York: Appleton.

Richerson, P. J. \& Boyd, R. (2005). Not by Genes Alone: How Culture Transformed Human Evolution. Chicago: Chicago University Press.

Riesch, R., Barrett-Lennard, L. G., Ellis, G. M., Ford, J. K. B. \& Deecke, V. B. (2012) Cultural traditions and the evolution of reproductive isolation: ecological speciation in killer whales? Biol. J. Linn. Soc. 106: 1-17.

Rieseberg, L.H., Raymond, O., Rosenthal, D.M., Lai, Z., Livingstone, K., Nakazato, T., Durphy, J.L., Schwarzbach, A.E., Donovan, L.A., and Lexer, C. (2003) Major ecological transitions in wild sunflowers facilitated by hybridization. Science 301:1211-1216.

Robinette, R. L. \& Ha, J. C. (1997). The significance of fishing by northwestern crows. Wilson Bulletin, 109, 748-749

Russon, A. E. (2003) Innovation and creativity in forest-living rehabilitant orang-utans In: Animal Innovation (eds Reader, S. M. \& Laland, K. N.). 279-306 Oxford University Press, New York, NY.

Sargeant, B. L. \& Mann, J. (2009) Developmental evidence for foraging traditions in wild bottlenose dolphins. Anim. Behav. 78: 715-721. 
1001

1002

1003

1004

1005

1006

1007

1008

1009

1010

1011

1012

1013

1014

1015

1016

1017

1018

1019

1020

1021

1022

1023

1024

1025

1026

1027

1028

1029

1030

1031

Sarin, S. and Dukas, R. (2009). Social learning about egg laying substrates in fruit flies. Proc. R. Soc. Lond. B 276:4323-4328.

Sasaki, T. \& Biro, D. (2017) Cumulative culture can emerge from collective intelligence in animal groups. Nature Communications, 8, 15049.

Schardien, B. J. \& Jackson, J. A. (1982). Killdeers feeding on frogs. Wilson Bulletin, 94, 85-87.

Seehausen, O. (2004). Hybridization and adaptive radiation. Trends in Ecology \& Evolution 19: 198-207.

Seeley, T. (1977) Measurement of nest cavity volume by the honey bee (Apis mellifera). Behavioral Ecology and Sociobiology, 2, 201-227.

Seeley, T.D. \& Buhrman, S.C. (2001) Nest-site selection in honey bees: how well do swarms implement the "best-of-n" decision rule? Behavioral Ecology and Sociobiology, 49, 416-427.

Seppanen, J., Forsman, J., Monkkonen, M., et al. (2011) New behavioural trail adopted or rejected by observing heterospecific tutor fitness. Proc. R. Soc. B 278:1736-1741.

Shettleworth, S. (2000). Modularity and the evolution of cognition. In C. Heyes \& L. Huber (Eds.), The Evolution of Cognition (pp. 43-60). Cambridge, MA: MIT Press.

Skinner BF (1938) The behavior of organisms. Appleton Century Crofts.

Skinner BF 1953. Science and Human Behavior. The Free Press: New York, NY.

Snell-Rood EC, Kobiela ME, Sikkink KL, Shepherd AM. (2018) Mechanisms of plastic rescue in novel environments. Ann. Rev. Ecol. Evol. Syst. 49, 331 - 354.

Sol, D., D. G. Stirling, and L. Lefebvre. (2005) Behavioral drive or behavioral inhibi- tion in evolution: subspeci c diversi cation in Holarctic passerines. Evolution 59:2669-2677.

Staddon J.E.R. (2007) Is Animal Learning Optimal?. In: Constructal Theory of Social Dynamics. Springer, Boston, MA

Staddon JER (2016) Adaptive Behavior and Learning. $2^{\text {nd }}$ Edition. Cambridge University Press.

St Clair, JJH, Klump, BC, Sugasawa, S, Higgott, CG, Colegrave, N \& Rutz, C (2018) 'Hook innovation boosts foraging efficiency in tool-using crows' Nature Ecology and Evolution, vol 2, pp 441-444. DOI: 10.1038/s41559-017-0429-7

Stephens, D. W. \& Krebs, J. R. (1986). Foraging Theory. Princeton, NJ: Princeton University Press. 
Stephenson G (1967) Cultural acquisition of a specific learned response among rhesus monkeys. In D Starck, R Schneider \& H Kuhn (eds.) Progress in Primatology. Stuttgart: Gustav Fisher Verlag.

Sullivan, A. P., Bird, D. W., \& Perry, G. H. (2017). Human behaviour as a long-term ecological driver of non-human evolution. Nature Ecology \& Evolution, 1, 0065.

Sultan, S. (forthcoming) Genotype-environment interaction and the unscripted reaction norm. In: Evolutionary Causation, edited by KN Laland and T Uller. MIT Press, Cambridge, MA.

Sutton, R. S., \& Barto, A. G. (1998). Reinforcement learning: An introduction. Cambridge, MA: MIT Press.

ten Cate C \& Rowe C (2007) Biases in signal evolution: learning makes a difference. Trends Ecol. Evol. 22(7): 380-7

Thorndike, E. L. (1898) Animal intelligence: An experimental study of the associative processes in animals. Psychological Review Monographs, 2 (Whole No. 8).

Thornton A \& Raihani NJ (2010) Identifying teaching in wild animals. Learning \& Behavior 38(3): 297-309

Thorogood, R. \& Davies, N. B. (2012) Cuckoos combat socially transmitted defenses of reed warbler hosts with a plumage polymorphism. Science 337: 578-580.

Todd, P. M. G. (1991) Exploring adaptive agency II: simulating the evolution of associative learning, pp. 306-315 in From Animals to Animals: Proceedings of the First International Conference on Simulation of Adaptive Behavior, edited by J. M. S. Wilson. MIT Press, Cambridge, MA.

Uller T, Moczek AP, Watson RA, Brakefield PM, Laland KN. 2018. Developmental bias and evolution: A regulatory network perspective. Genetics 209 (4): 949-966

van der Graaf, A.J., Stahl, J., Klimkowska, A., Bakker, J.P. \& Drent, R.H. (2006) Surfing on a green wave: how plant growth drives spring migration in the barnacle goose. Ardea, 94, 567-577.

Vansteelant, W.M.G., Kekkonen, J. \& Byholm, P. (2017) Wind conditions and geography shape the first outbound migration of juvenile honey buzzards and their distribution across sub-Saharan Africa. Proceedings. Biological sciences, 284, 20170387.

Verziijden MN, ten Cate C, Servedio MR, Kozak GM, Boughman JW \& Svensson El (2012) The impact of learning on sexual selection and speciation. Trends. Ecol. Evol. 27(9): 511-9 
1064 Vieth W, Curio E \& Ernst U (1980) The adaptive significance of avian mobbing. III. Cultural transmission of enemy recognition in blackbirds: Cross-species tutoring and properties of learning. Anim. Behav. 28: 1217-29

Warner, R. R. (1988) Traditionality of mating-site preferences in a coral reef fish. Nature 335: 719-721.

Warner, R. R. (1990) Male versus female influences on mating-site determination in a coralreef fish. Anim. Behav. 39: 540-548.

Weber E, Shafir S, \& Blais A (2004) Predicting Risk Sensitivity in Humans and Lower Animals: Risk as Variance or Coefficient of Variation. Psych. Rev., 111, 430-445. (doi: 10.1037/0033-295X.111.2.430)

West-Eberhard, M. J. (2003) Developmental plasticity and evolution. (Oxford University Press, Oxford, UK.

Whalen A, Cownden D \& Laland KN (2015) The learning of action sequences through social transmission. Animal Cognition DOI 10.1007/s10071-015-0877-x.

Whitehead, H. (1998) Cultural selection and genetic diversity in matrilineal whales. Science 282: 1708-1711.

Whitehead H, Laland KN, Rendell L, Thorogood R \& Whiten A (2019) The reach of gene-culture coevolution in animals. Nature Communications. 10: 2405

Whiten, A., Ayala, F.J., Feldman, M.W. \& Laland, K.N. (2017) The extension of biology through culture. Proceedings of the National Academy of Sciences 114: 7775-7781.

Wilkinson, G. (1992). Information transfer at evening bat colonies. Anim. Behav. 44: 501-518. 


\begin{tabular}{|c|c|}
\hline Category & Examples \\
\hline $\begin{array}{l}\text { Developmental variation biased } \\
\text { towards adaptive outcomes }\end{array}$ & $\begin{array}{l}\text { - Reinforcement learning (Staddon, 2007) } \\
\text { - Adaptive filtering and biased cultural transmission (Enquist \& } \\
\text { Ghirlanda, 2007; Rendell et al. 2010) } \\
\text { Teaching behavior in ants, bees, meerkats and pied babblers (Hoppitt } \\
\text { et al 2008; Thornton \& Raihani, 2010) }\end{array}$ \\
\hline $\begin{array}{l}\text { Historical bias } \\
\text { Developmental variation biased } \\
\text { by historical legacy (e.g. } \\
\text { ancestral selection, or tradition) }\end{array}$ & $\begin{array}{l}\text { Rats avoid taste or smell of poisoned food, but are slow to learn that } \\
\text { a sound or light predicts illness (Garcia \& Koelling 1966). } \\
\text { Lab-reared rhesus monkeys learn a fear of snakes more readily than } \\
\text { a fear of arbitrary objects, after watching conspecifics behaving } \\
\text { fearfully (Mineka and Cook,1988; but see Stephenson 1967). } \\
\text { Raccoons could not be conditioned to pick up coins and place them } \\
\text { in a money box for a food reward (Breland \& Breland, 1961). }\end{array}$ \\
\hline $\begin{array}{l}\text { Origination bias } \\
\text { Developmental variation biased } \\
\text { in its origination }\end{array}$ & $\begin{array}{l}\text { - Juveniles of some migratory birds exhibit more route variation than } \\
\text { older individuals (Mueller et al., 2013; Oppel et al., 2015; Vansteelant } \\
\text { et al., 2017) } \\
\text { The inventors of novel behavior are usually more likely to be } \\
\text { experienced individuals than youngsters in nonhuman primates } \\
\text { (Reader \& Laland, 2001; Kendal et al, 2005), and more commonly low- } \\
\text { ranking than dominants (Reader \& Laland, 2001). } \\
\text { Innovativeness of monkey species was predicted by their reliance on } \\
\text { extractive foraging (Kendal et al, 2005) }\end{array}$ \\
\hline $\begin{array}{l}\text { Transmission bias } \\
\text { Biased transmission of } \\
\text { developmental variation, with } \\
\text { some forms being propagated } \\
\text { more readily than others }\end{array}$ & $\begin{array}{l}\text { Red-winged blackbirds copy feeding conspecifics except when they } \\
\text { show an aversive reaction to food (Mason \& Reidinger 1982). } \\
\text { Bats unsuccessful at locating food alone follow successful bats to } \\
\text { feeding sites, using cues indicative of feeding, e.g. defecation } \\
\text { (Wilkinson, 1992). } \\
\text { Insects and birds copy the nest-site decisions of successful } \\
\text { conspecifics and heterospecifics (Sarin \& Dukas, 2009; Pasqualone \& } \\
\text { Davis, 2011; Seppanen et al 2011; Forsman \& Seppanen, 2011). }\end{array}$ \\
\hline $\begin{array}{l}\text { Variational bias } \\
\text { Developmental processes bias } \\
\text { evolutionary processes through } \\
\text { generating some phenotypic } \\
\text { forms more readily than others }\end{array}$ & $\begin{array}{l}\text { - Culturally transmitted dietary traditions in killer whale have favored } \\
\text { population-specific genes influencing morphology and digestion, } \\
\text { (Foote et al., 2016; Hoelzel \& Moura, 2016). } \\
\text { Mate choice copying influences sexual selection of male traits (Gibson } \\
\text { et al., 1991; Kirkpatrick \& Dugatkin, 1994; Nöbel et al., 2018). } \\
\text { Reed warbler learning drives the evolution of plumage patterns in } \\
\text { cuckoos (Davies \& Welbergen, 2009; Thorogood \& Davies, 2012). }\end{array}$ \\
\hline $\begin{array}{l}\text { Developmental processes bias } \\
\text { evolutionary processes through } \\
\text { generating some environmental } \\
\text { states more readily than others } \\
\text { (niche construction) }\end{array}$ & $\begin{array}{l}\text { Dairy farming created selection alleles for adult lactase persistence } \\
\text { (Gerbault et al, 2011) } \\
\text { Agricultural practices (e.g. cultivating yams) have inadvertently } \\
\text { promoted the spread of malaria in some populations, leading to } \\
\text { selection of the HbS allele which confers resistance (Durham, 1991). } \\
\text { The farming and consumption of starchy foods has favored high copy } \\
\text { number of AMY1, which facilitates the breakdown of the excess } \\
\text { starch in agricultural diets (Perry et al, 2007). }\end{array}$ \\
\hline
\end{tabular}

1091 Table 1. Categories of developmental bias generated by learning, with examples (see text for 1092 details). 